\title{
ANÁLISE DA PRECIPITAÇÃO ATRAVÉS DO USO DE TÉCNICAS MULTIFRACTAL EM PERÍODOS CHUVOSOS E SECOS NO MÉDIO E BAIXO CURSO DAS BACIAS DOS RIOS TIETÊ E PARANAPANEMA (SP)
}

\author{
CHRISTOFOLETTI, Anderson Luis Hebling - ander.christo@gmail.com \\ Universidade Estadual Paulista / UNESP - Rio Claro
}

FONTÃO, Pedro Augusto Breda - pedrofontao@yahoo.com.br Universidade Estadual Paulista / UNESP - Rio Claro

AZEVEDO, Thiago Salomão de - azevedots@gmail.com

Universidade Estadual Paulista / UNESP - Rio Claro

MAIA, Diego Correa - maiaunesp@gmail.com

Universidade Estadual Paulista / UNESP - Rio Claro

NASCIMENTO, Melchior Carlos do - melchior.nascimento@igdema.ufal.br Universidade Federal do Alagoas / UFAL

MEGDA, Otávio Reis - otavio.megda@hotmail.com

Pontíficia Universidade Católica de Campinas / PUCCampinas

\begin{abstract}
RESUMO: A presente pesquisa analisa a aplicação das técnicas de origem multifractal para semestres chuvosos e secos em anos-padrão, identificados respectivamente como chuvoso, habitual e seco, na região do médio e baixo curso da bacia do rio Tietê e no setor paulista da bacia do rio Paranapanema. Seguindo esta premissa, foi realizada uma análise espacial das chuvas por meio da elaboração de mapas de distribuição dos valores de dimensão fractal das precipitações, para os limiares de 0,1, 10, 20 e 40 milímetros. No geral, notou-se na área de estudo uma diminuição do número de dias com ocorrência de chuva conforme aumentou-se os limiares, mostrando-se compatível com o índice de participação obtido em outros estudos e podendo gerar indicadores numérico coerentes com o ritmo pluviométrico e a dinâmica das chuvas nestas áreas.
\end{abstract}

Palavras-chave: Precipitação, Geometria Multifractal, Climatologia.

ANALYSIS OF PRECIPITATION THROUGH THE USE OF MULTIFRACTAL TECHNIQUES IN RAINY AND DRY PERIODS IN THE MIDDLE AND LOWER COURSE OF TIETÊ RIVER AND PARANAPANEMA RIVER BASIN (SP, BRAZIL)

ABSTRACT: This research analyzes the application of the techniques of multifractal origin for rainy and dry semesters in standard-years, respectively identified as rainy, usual and dry, in the region of the middle and lower course of the Tietê river basin and Paranapanema river basin in the state of São Paulo, Brazil. Following this premise, a spatial analysis of the rains was carried out through the elaboration of distribution maps of the fractal dimension values of the precipitations, for the thresholds of $0.1,10,20$ and 40 millimeters. In general, it was observed in the study area a decrease in the number of days with rainfall as the thresholds were increased, being compatible with the participation index obtained in other studies, and could generate numerical indicators consistent with the rainfall and atmospheric dynamics in these areas.

Keywords: Precipitation, Multifractal Geometry, Climatology.

ANÁLISIS DE LA PRECIPITACIÓN A TRAVÉS DEL USO DE TÉCNICAS MULTIFRACTALES EN PERÍODOS LLUVOSOS Y SECOS EN EL MEDIO Y BAJO CURSO DE LAS BACIAS DE LOS RIOS TIETÊ Y PARANAPANEMA (SP, BRASIL) 
RESUMEN: Esta investigación analiza la aplicación de las técnicas de origen multifractal para los semestres lluviosos y secos en "años estándar", identificados respectivamente como lluvioso, habitual y seco, en la región del curso medio e inferior de la cuenca del río Tietê y del río Paranapanema en el estado de São Paulo, Brasil. Siguiendo esta premisa, se realizó un análisis espacial de las lluvias mediante la elaboración de mapas de distribución de los valores de dimensión fractal de las precipitaciones, para los umbrales de $0,1,10,20$ y 40 milímetros. En general, se notó en el área de estudio una disminución del número de días con ocurrencia de lluvia conforme se aumentó los umbrales, mostrándose compatible con el índice de participación obtenido en otros estudios y pudiendo generar indicadores numéricos coherentes con la lluvia y la dinámica atmosférica en estas áreas.

Palabras-Clave: Precipitación, Geometría Multifractal, Climatología.

ANALYSE DES PRÉCIPITATIONS PAR L'UTILISATION DE TECHNIQUES MULTIFRACTALES DANS LES PÉRIODES DE PLUIE ET SĖCHES DANS LE MOYEN ET FAIBLE COURS DES BIAIS DE RIO TIETÊ ET PARANAPANEMA (SP, BRÉSIL)

RESUMÉ: La présente étude analyse I'application de techniques d'origine multifractale pour les semestres pluvieux et secs en années-normales, identifiées respectivement comme pluvieuses, habituelles et sèches, dans la région du cours moyen et inférieur du bassin de la rivière du Tietê et Paranapanema dans l'état de São Paulo, Brésil. Suite à cette prémisse, une analyse spatiale des pluies a été réalisée à travers l'élaboration de cartes de distribution des valeurs de dimension fractale des précipitations, pour les seuils de $0,1,10,20$ et 40 millimètres. En général, on a observé dans la zone d'étude une diminution du nombre de jours de précipitations lorsque les seuils étaient augmentés, compatible avec l'indice de participation obtenu dans d'autres études et pourrait générer des indicateurs numériques cohérents avec les précipitations et la dynamique atmosphérique dans ces zones.

Mots-Clés: Précipitation, Géométrie Multifractale, Climatologie

\section{INTRODUÇÃO}

Pode-se afirmar que a ciência se baseia em premissas que acabam por se tornar verdadeiras através do uso de métodos adequados para comprovar a hipótese proposta. No mundo ocidental, tal embasamento decorreu desde a antiguidade, através da civilização grega que acabou por exercer grande influência nas correntes de pensamento. Através disso, a elaboração de uma teoria inicia-se com uma hipótese e finaliza-se a uma conclusão podendo utilizar procedimentos e ideias lógicas simples ou complexas, até que a evidência seja demonstrada. Isto posto e levando em conta tais circunstâncias, pode-se considerar que a Geografia é a ciência que estuda as organizações espaciais, observando sempre a relação entre as variáveis ambientais e o ser humano.

Deste modo, a Geografia aborda a estruturação, funcionamento e dinâmica dos elementos ambientais e socioeconômicos. Como parte integrante da ciência geográfica, existe a Geografia Física que tem como objetivo a análise da organização espacial dos sistemas ambientais físicos, também denominados de geossistemas (SOTCHAVA, 1977). Dentre os métodos e técnicas voltadas à essas análises científicas, tem se destacado a teoria geral dos sistemas, que de maneira recente e específica, pode interagir com a teoria do caos e com a abordagem das técnicas de geometria dos fractais, que consistem em métodos recentes visando evidenciar e aprimorar as diversas perspectivas aplicadas na análise geográfica.

Nesse panorama, o clima ao ser considerado como elemento integrante do geossistema, não pode ser analisado como objeto materializável e visível na 
superfície terrestre, no entanto é algo perceptível para os seres vivos e contribui para visualizar os cenários paisagísticos do ambiente. Partindo desses pressupostos, o clima é o fator fundamental para o geossistema, pois é o fornecedor de energia, cuja incidência repercute na quantidade disponível de calor e água através do ciclo hidrológico em diferentes faixas latitudinais, em diversos tipos de superfícies durante as estações climáticas.

Do ponto de vista geográfico, ao se considerar toda a trajetória e a construção de um pensamento cientifico em âmbito nacional, deve-se reconhecer a existência de uma Climatologia Geográfica específica e singular produzida no Brasil (ZAVATTINI, 2004), derivada de uma escola de pensamento vinculada ao legado e aos desdobramentos das obras do professor Carlos Augusto de Figueiredo Monteiro (MONTEIRO, 2015). Tal concepção apresentou à climatologia nacional o paradigma do ritmo climático, além de uma reestruturação de caráter dinâmico às classificações climáticas, que concatenaram com a abordagem sistêmica através do movimento sazonal das massas de ar atuantes em várias localidades da superfície do planeta, considerando sempre sua escala de atuação.

Strahler (1951), ao propor sua classificação climática, preocupou-se com os processos de origem dinâmica e visou compreender a funcionalidade que opera o sistema climático nas macroescalas da superfície terrestre, a partir de três grandes faixas zonais do planeta influenciadas pela gênese das massas de ar. Monteiro (1969; 1973), ao longo das décadas de 1960 e 1970, aproximou-se do ponto de vista de Strahler e propôs avanços significativos no conhecimento dos climas brasileiros, sobretudo com relação aos mecanismos atmosféricos operantes sobre as atuais regiões Sul e Sudeste do país, com destaque para o estado de São Paulo, área de grande importância em relação à dinâmica entre as massas de ar e atuação intensa de mecanismos frontológicos.

Da mesma forma que se verifica ao longo do território brasileiro, no estado de São Paulo a precipitação em particular mostrou-se como um elemento dotado de grande variabilidade e sazonalidade, nesse caso apresentando certo destaque para a identificação das feições climáticas individualizadas a partir do ritmo e da gênese das chuvas. Desse modo, essa pesquisa propõe analisar a variação em nível temporal e espacial das precipitações através da abordagem fractal na região do médio e baixo curso das bacias hidrográficas do Tietê e Paranapanema, região oeste paulista dotada de importantes cidades e de grande relevância no setor agropecuário.

Para tanto, buscou-se analisar tal variável através da técnica aplicada por Olsson (1996), que é o cálculo da dimensão fractal pela contagem da frequência dos dias chuvosos por tamanho de segmentos, conforme diferentes magnitudes ou limiares, tanto em períodos secos quanto chuvosos. O estudo visa observar e verificar nuanças no interior da área de estudo a fim de discernir indicadores que possibilitem especificar seus contrastes, produzindo valores para cada local e criando condições para se analisar a variabilidade espacial e verificar a regionalização das chuvas em diferentes volumes e suas relações com a dinâmica climática.

Assim, espera-se contribuir para uma melhor compreensão sobre o comportamento das chuvas na estação chuvosa e seca e, a partir da análise da dimensão multifractal para diferentes limiares de volume precipitado em nível diário, produzir indicadores que permitam o estudo comparativo das séries 
temporais em anos padrão (extremos e habitual) sobre a estrutura da precipitação das estações chuvosas e secas. Tal como Christofoletti (1997), relacionar os resultados da análise multifractal à classificação climática estabelecida por Monteiro (1973).

\subsection{A TEORIA DOS SISTEMAS, A TEORIA DO CAOS DETERMINÍSTICO, A GEOMETRIA DOS FRACTAIS E OS ESTUDOS DE PRECIPITAÇÃO}

A perspectiva holística mais desenvolvida e abrangente no cenário das atividades geossistêmicas encontra-se relacionada com a análise de sistemas ambientais, oriundas das contribuições de Bertalanffy (1973) com base na Biologia teorética e de Prigogine (1990) apoiado nos sistemas dinâmicos da Física e Química. Chorley e Kennedy (1971, apud CHRISTOFOLETTI, 1999, p.5) salientaram o aspecto conectivo do conjunto, formando uma unidade, ao apontar que:

\footnotetext{
"Um sistema é um conjunto estruturado de objetos e ou atributos. Esses objetivos e atributos consistem de componentes ou variáveis (Isto é, fenômenos que são passíveis de assumir magnitudes variáveis) que exibem relações discerníveis um com os outros e operam conjuntamente como complexos, de acordo com determinado padrão".
}

Também Haigh (1985, apud CHRISTOFOLETTI, 1999, p.5) ao fazer uma breve revisão sobre tal teoria, assinalou que um sistema seria a totalidade que é criada através da "integração de um conjunto estruturado de partes componentes, cujas inter-relações estruturais criam uma incerteza que não se encontra implicada por aquelas partes componentes quando desagregadas". Considerado que o clima surge como o controlador dos processos e da dinâmica do geossistema, mas não como elemento intrínseco e integrante da organização espacial, essa noção pode ser operacionalizada sob diversas grandezas na escala espacial e temporal.

Até a década de 1960, Gleick (1990) afirmava que havia um paradigma newtoniano para a análise dos comportamentos físicos na natureza no qual estava contida a ideia de previsibilidade determinista, ou seja, tudo era previsível se aplicasse as leis corretas da matemática. Entretanto, os erros assinalados eram devidos à aleatoriedade que resultavam em pequenas distorções. Pereira e Christofoletti (2003) observaram que os cientistas achavam que, com dados aproximados, chegariam ao comportamento aproximado da realidade, sem distorções graves com o passar do tempo.

Entretanto, Lorenz (1996), particularmente em sua obra "A essência do caos", demonstra o comportamento caótico que ocorre em sistemas dinâmicos e não lineares, como é o caso das variáveis atmosféricas. Tais experiências contribuíram para uma alteração no paradigma vigente de sua época, à medida que se constatou que as equações matemáticas da atmosfera, outrora consideradas simples, poderiam gerar grandes distorções aparentemente caóticas e imprevisíveis no processo de repetição com pequenas diferenças nos valores iniciais consideradas desprezíveis.

A pesquisa a respeito da teoria do caos somente pôde ser realizada graças ao uso do computador, mesmo que considerado rudimentar 
comparado aos dias atuais. A aplicação de simples modelos com apenas três intempéries para a previsão do tempo necessitava de uma grande quantidade de dados inseridos antecipadamente. Ao gerar novos gráficos de modelos de previsão, o autor inseriu os mesmos dados de uma experiência realizada anteriormente e, para simplificar, digitou três casas após a virgula, sendo que o primeiro modelo continha seis casas. No início, no novo gráfico, surgiram curvas semelhantes ao anterior, no entanto com o passar do tempo as curvas não apresentaram comportamentos extremamente diversos. Lorenz (apud CHRISOTOFOLETTI, 2004, p.95) denominou de "dependência sensível das condições iniciais" ou "efeito borboleta". Assim, a previsão do tempo para longo prazo seria inviável já que "os erros e as incertezas se multiplicam com o passar do tempo".

A aleatoriedade descrita anteriormente apresenta certa ordem, todavia era necessário compreender como essa ordem se expressava através de fórmulas matemáticas, para compreender os fenômenos complexos não lineares existentes na natureza. De acordo com Peitgen et al. (1992), "o determinismo restrito e o desenvolvimento aparentemente acidental não são mutuamente exclusivos, mas a sua coexistência constitui a regra na natureza". Posteriormente, a partir dos desdobramentos teóricos, Guerrini (1996) afirmou que a dinâmica dos sistemas complexos não lineares engloba o estudo do caos determinístico.

Desse modo, desde a década de 1970 um novo tipo de abordagem analítica tem sido utilizada nas ciências naturais, sociais e aplicadas: a geometria dos fractais, desenvolvida inicialmente pelo matemático francopolonês Mandelbrot (1975; 1982), cujos principais conceitos e ideias sobre o assunto foram publicados somente em 1975 com a obra "Les objets fractals: forme, hasard et dimension", posteriormente traduzida para o inglês em 1977, e revisada e ampliada na edição de 1982, agora sob novo título "The fractal geometry of nature".

A geometria fractal relaciona-se com o conhecimento da estrutura, forma e composição dos sistemas nas suas mais diversas complexidades, ligando-se com as concepções dos sistemas dinâmicos e teoria do caos. Pode-se afirmar que a geometria fractal analisa as formas da estrutura que são resultantes de fenômenos e processos caóticos. A respeito dela, Christofoletti (2004, p. 98) afirma que "os fractais são a expressão geométrica para o caos determinístico, ou seja, são formas estruturais resultantes de processos caóticos e geralmente estas formas são originadas de uma dinâmica caótica, imprevisível, aleatória".

Lorenz (1996) destacou que a formas aparentemente irregulares geradas pela geometria fractal possuem regularidade ao relacionar com os sistemas dinâmicos não-lineares, denominados como caóticos e essas regularidades apresentam ordem na aleatoriedade previamente analisada por outras abordagens científicas. Para a análise dos elementos sistêmicos na geometria fractal deve-se destacar que esta apresenta duas características fundamentais: a auto similaridade que é a extensão para a qual o relacionamento entre o número de elementos constitutivos e suas medidas é verdadeiramente linear; além da existência da invariância escalar que representa a linearidade entre os valores obtidos nas diversas escalas de mensuração (CHRISTOFOLETTI, 1997).

O emprego de técnicas de geometria fractal e multifractal na medição e análise das precipitações pode ser feita em diversos segmentos temporais, os 
quais compõem estruturas e representam objetos que podem ser avaliados por esse tipo de estratégia metodológica. Tal abordagem pode contribuir para o reconhecimento de padrões de distribuição e segmentação das chuvas ao longo do tempo, sugerindo novas maneiras de explorar os processos de frequência, intensidade e duração do fenômeno pluvial e, dessa maneira, relacioná-lo às repercussões do mesmo no espaço geográfico como, por exemplo, os eventos extremos e os impactos decorrentes. Isto posto, diversos são os estudos no âmbito da climatologia que contemplam tais mecanismos, podendo-se citar Christofoletti (1997), Pereira e Christofoletti (2003), Kantelhardt et al., (2006), Jebari et al. (2012), Mello et al. (2013), Xavier Júnior et al. (2018), dentre diversos outros como exemplos de aplicação.

\section{2. ÁREA DE ESTUDO E SUAS CARACTERÍSTICAS FÍSICAS}

A área selecionada para a realização desse estudo consiste em parte das bacias hidrográficas do Tietê e do Paranapanema, região de grande importância para a agropecuária brasileira e na produção de energia hidrelétrica, atividades que dependem diretamente das chuvas, tanto em volume quanto em distribuição temporal. Da mesma maneira, sua dimensão em escala regional e a localização face à uma área de circulação atmosférica altamente dinâmica contribuiu para essa escolha. Para não entrar no mérito de diferentes regionalizações, adotou-se a divisão proposta pelas Unidades Hidrográficas de Gerenciamento de Recursos Hídricos do estado de São Paulo (SIGRH, 2017), optando pela área hidrográfica do Médio e Baixo curso do rio Tietê e pela vertente paulista da bacia do Paranapanema, conforme ilustrado na Figura 1.

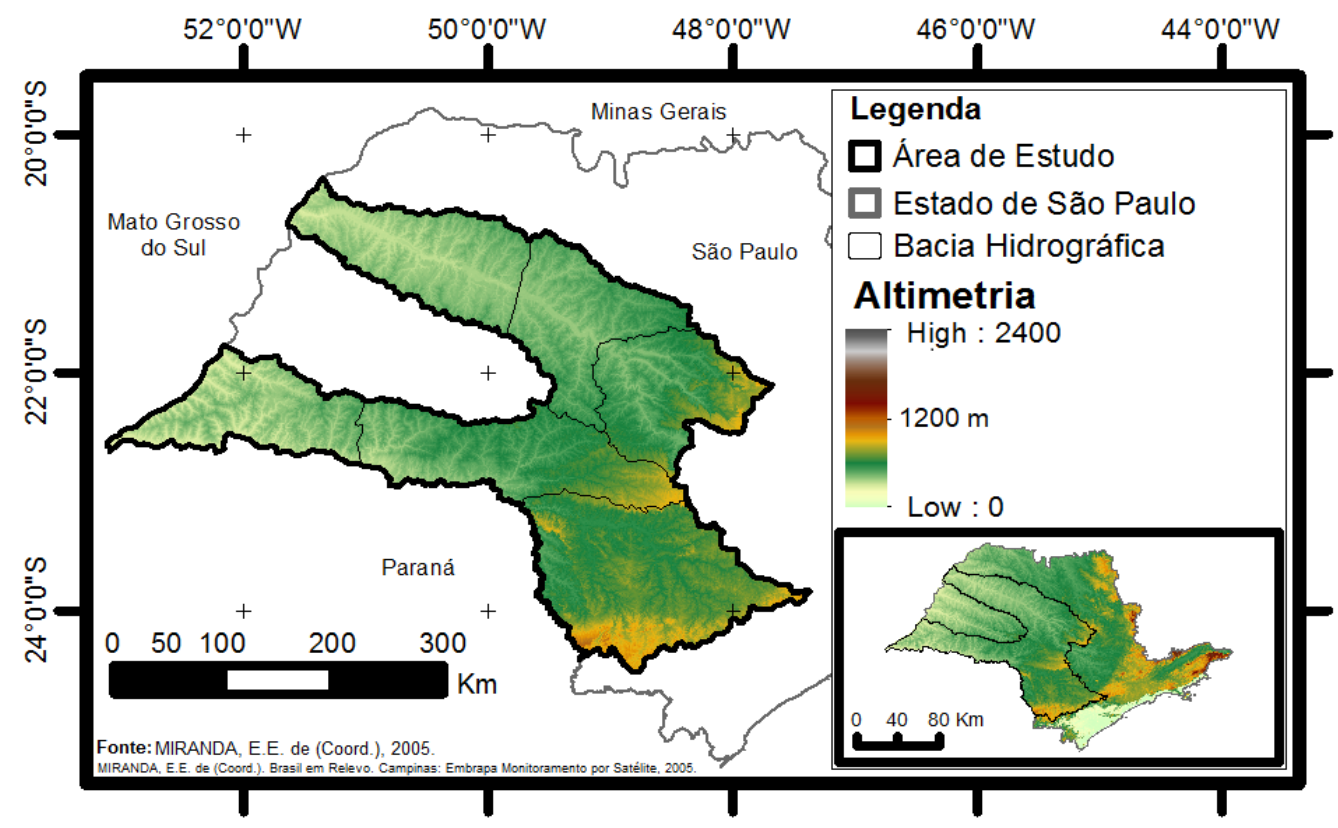

Figura 1 - Área de estudo (interior das bacias dos rios Tietê e Paranapanema) e a altimetria regional.

A bacia hidrográfica do Tietê é a maior do estado de São Paulo com área de aproximadamente $72.000 \mathrm{~km}^{2}$, subdividindo-se em um total de seis sub- 
bacias e, dentre elas, foram selecionadas para o presente estudo os setores Tietê/Jacaré, Tietê/Batalha e Baixo Tietê, respectivamente dispostos no sentido Leste-Oeste. Trata-se de uma região drenada pelo rio Tietê, rio principal cuja nascente localiza-se no município de Salesópolis-SP a, aproximadamente, 1.120 metros de altitude e suas águas atravessam o estado de São Paulo alongandose na direção Leste-Oeste, percorrendo mais de 3,7 mil quilômetros antes de chegar ao estuário do rio da Prata, por meio do rio Paraná (BRASIL, 2017).

Em relação à bacia hidrográfica do Paranapanema, área de grande relevância cuja principal drenagem é o rio Paranapanema, sua nascente localizase em Capão Bonito - SP e apresenta extensão aproximada de 930 quilômetros, dos quais cerca de 330 quilômetros dela formam a divisa natural entre os estados de São Paulo e Paraná. Localiza-se na região do Alto Rio Paraná e estende-se pelo sudoeste do estado de São Paulo e norte paranaense, cobrindo uma área de, aproximadamente, $100.800 \mathrm{~km}^{2}$, dos quais, $53 \%$ estão no território do Paraná e $47 \%$ na porção paulista, segundo Brasil (1984). No estado de São Paulo, trata-se da segunda maior bacia paulista e desmembra-se em três sub-bacias, respectivamente no sentido Leste-Oeste: Alto Paranapanema, Médio Paranapanema e Baixo Paranapanema.

Com base em Christofoletti (1980), infere-se que as duas bacias em questão apresentam drenagens que podem ser classificadas com exorréicas e seus rios principais classificados como consequentes. Sendo que estes rios compõem uma drenagem paralela, por formarem cursos de lineamento reto em direção às baixadas. Para o autor (CHRISTOFOLETTI, 1980, p.105), tal tipo de drenagem "localiza-se em áreas onde há presença de vertentes com declividades acentuadas ou onde existem controles estruturais que motivam a ocorrência de espaçamento regular, quase paralelo, das correntes fluviais".

$\mathrm{Na}$ classificação climática para o estado de São Paulo proposta por Monteiro (1973) é possível observar que, ao norte da área de estudo, a bacia do Tietê apresenta a maior parte do seu interior situado na faixa climática sob o domínio de climas controlados por massas equatoriais e tropicais, apresentando climas alternadamente secos e úmidos na percée do Tietê e no oeste do estado. No entanto, localizada mais ao sul do estado, a bacia do Paranapanema apresenta a maior parte da sua área situada na faixa climática dominada por climas controlados por massas tropicais e polares, considerada como subtropical continental. Desse modo, as duas bacias apresentarem a maior parte de suas áreas situadas em faixas climáticas distintas.

Para Ab'Saber (2003), as nascentes e parte das bacias do Tietê e a do Paranapanema estão sob o domínio morfoclimático de mares de morros, que se refere a áreas mamelonares tropical-atlânticas florestadas, mas estas se encontram atualmente muito degradadas devido à intensa urbanização, industrialização e atividades agrícolas e pecuárias. No entanto, a área a ser analisada abrangerá parte dos compartimentos geomorfológicos da província de cuestas basálticas e do planalto ocidental, formados por rochas sedimentares.

\section{MATERIAIS E METOdOLOGIA DA PESQUISA}

A primeira etapa para a realização da pesquisa consiste em, a partir da área de estudo previamente estabelecida, identificar um período de análise que contemple grande variabilidade em termos de precipitação, tanto para os 
semestres secos quanto para os chuvosos no nível anual. Para tanto, optou-se pela proposta dos anos padrão sugerida inicialmente por Monteiro (1973), que propõe o uso de anos representativos em termos de precipitação (habitual ou excepcionais - secos ou chuvosos), e busca-se na dissertação de Zandonadi (2009), no qual o autor aplicou o método da fórmula de Sturges para determinar classes e, posteriormente, elencar os anos padrão para a região da área de estudo (bacia do Paraná), para identificar o triênio 1983, 1984 e 1985 como anos padrão chuvoso, habitual e seco, respectivamente e em sequência.

No estado de São Paulo, pode-se verificar no seu regime hidrológico anual dois grandes períodos, um semestre úmido dotado de chuvas concentradas entre outubro e março e um período de estiagem compreendido entre abril e setembro, conforme sugere Sant'Anna Net (1995). Desse modo, embora seja possível em cada ano ocorrer variações tanto no início quanto no final das estações chuvosas, conforme foi mostrado na análise sobre a sazonalidade da precipitação na bacia do Piracicaba (CHRISTOFOLETTI, 1992) e na bacia do Pardo (FONTÃO e ZAVATTINI, 2017), visando uma uniformidade da extensão do período envolvido na análise utilizou-se como referencial os meses de outubro a março para a estação chuvosa e abril a setembro para a estação seca.

Assim, para facilitar o uso da técnica de análise da estrutura da estação chuvosa, o tamanho da unidade inicial foi considerado como sendo de 192 dias. Para isso, foram incluídos alguns dias antes e depois do início oficial da estação austral dos períodos secos e chuvosos supracitados, tendo como limiar o total de 6 dias. Dessa maneira, no período chuvoso encontram-se considerados 96 dias na primeira fase (ano precedente) e 96 dias na segunda fase (ano posterior). Do mesmo modo, a estação seca contou com os mesmos 192 dias, incluindo a soma de dias anteriores e posteriores conforme critério similar.

Para se realizar o procedimento da abordagem multifractal nos períodos secos e chuvosos foi aplicado o uso de frequência média dos dias chuvosos por tamanho de segmento em diferentes limiares, em milímetros. Tal procedimento encontra-se vinculado a proposição apresentada por Mayer (1992) e representa ajustagem técnica relacionada com a contagem funcional de blocos. $O$ procedimento consiste em realizar a fragmentação sucessiva do tamanho da unidade inicial em segmentos cada vez menores e contar a frequência dos dias chuvosos (acima de 0,1 $\mathrm{mm}$ ) em cada tamanho de segmento. Leva-se em consideração apenas um limiar de magnitude para caracterizar a presença de dia com precipitação.

No que se refere à análise da estrutura da estação chuvosa e seca, de 192 dias cada, a primeira etapa consiste em estabelecer a divisão dos segmentos temporais adequados (OLSSON, 1996). Torna-se oportuno realizar a divisão sucessiva por dois, de modo que os comprimentos dos períodos ficam sendo de 192, 96, 48, 24, 12, 06, 03 e 1 dia. A segunda etapa consistiu em registrar a quantidade de dias chuvosos ocorridos em cada segmento. Em terceiro, calcula-se a média dos dias chuvosos ocorridos para cada categoria de tamanho dos segmentos, levando-se em conta apenas os preenchidos por eventos e desconsiderando os segmentos vazios. A quarta etapa consiste em construir tabela e gráfico tomando como base os logaritmos dos tamanhos de segmentos $(t)$, em dias, versus os logaritmos da grandeza dos segmentos $(m)$, que são as quantidades médias de dias chuvosos. Na análise multifractal, os 
limiares estabelecidos nesse estudo foram precipitações diárias com valores acima de $0,1 \mathrm{~mm}, 10 \mathrm{~mm}, 20 \mathrm{~mm}$ e $40 \mathrm{~mm}$, adotando-se no mapeamento dos resultados uma escala de cor para cada limiar, devido às diferenças evidentes nos valores finais.

A partir dos procedimentos detalhados, foi realizado o levantamento, compilação e escolha dos postos pluviométricos a serem utilizados no estudo através de elenco fornecido pela rede administrada pelo Departamento de Águas e Energia Elétrica do Estado de São Paulo (DAEE, 2017). Para essa etapa, houve a necessidade de realizar a escolha dos postos pluviométricos que representassem a série de dados completa e sem falhas para os anos-padrão escolhidos na área de estudo, compreendido entre o início do outono de 1983 até o fim do verão de 1986, abrangendo um mês anterior e posterior ao intervalo supracitado. O mapa da Figura 2 ilustra a distribuição dos postos selecionados na área de estudo e a Tabela 1 permite visualizar o nome e respectivos dados de localização dos mesmos.

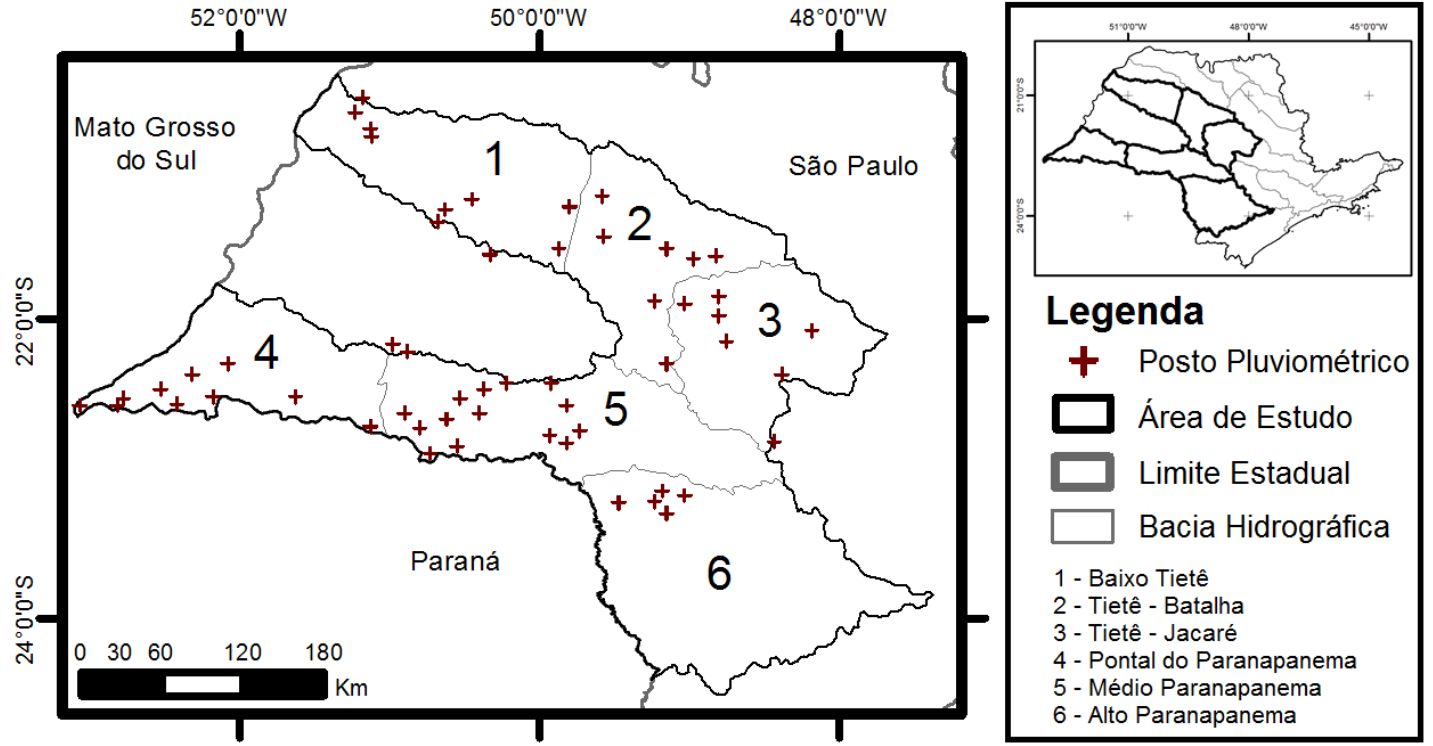

Figura 2 - Distribuição dos postos pluviométricos na área de estudo.

Inicialmente, o intuito seria uma distribuição homogênea desses postos entre as bacias, no entanto devido à dificuldade de obter dados sem falhas em nível diário, em particular em alguns setores da bacia do Paranapanema, foram priorizados e selecionados os postos pluviométricos com dados contínuos. O Alto Paranapanema, área com menor densidade de postos, concentrou seus postos pluviométricos na porção setentrional de sua extensão e próxima ao Médio Paranapanema, fator que foi considerado ao realizar as análises desse estudo.

Em relação aos materiais utilizados para a pesquisa, as tabelas e organização dos dados para a aplicação da técnica multifractal foram feitas através do software Microsoft Excel 2013. Para os procedimentos de mapeamento e espacialização dos resultados, utilizou-se a krigagem ordinária pelo software Golden Surfer 13 . No que se refere às etapas de ilustração e 
acabamento das figuras, tal procedimento foi realizado através dos softwares ESRI ArcGIS 10.2.2. e CorelDRAW 12.

Tabela 1 - Postos pluviométricos utilizados no estudo.

\begin{tabular}{|c|c|c|c|c|c|c|c|c|c|}
\hline Num. & Código DAEE & Altitude & Lat. & Long. & Num. & Código DAEE & Altitude & Lat. & Long. \\
\hline 1 & $\mathrm{~B} 8-032$ & 350 & $-20,52$ & $-51,18$ & 29 & D7-046 & 680 & $-22,43$ & $-50,22$ \\
\hline 2 & B8-025 & 340 & $-20,62$ & $-51,23$ & 30 & D7-066 & 490 & $-22,47$ & $-50,37$ \\
\hline 3 & B8-001 & 350 & $-20,73$ & $-51,13$ & 31 & D9-022 & 310 & $-22,47$ & $-52,53$ \\
\hline 4 & B8-030 & 380 & $-20,78$ & $-51,12$ & 32 & D8-016 & 320 & $-22,52$ & $-51,63$ \\
\hline 5 & C6-036 & 490 & $-21,18$ & $-49,58$ & 33 & D9-003 & 350 & $-22,52$ & $-52,18$ \\
\hline 6 & C7-009 & 390 & $-21,20$ & $-50,45$ & 34 & D7-076 & 460 & $-22,53$ & $-50,53$ \\
\hline 7 & C6-089 & 380 & $-21,25$ & $-49,80$ & 35 & D9-023 & 300 & $-22,53$ & $-52,78$ \\
\hline 8 & C7-033 & 410 & $-21,27$ & $-50,63$ & 36 & D9-014 & 300 & $-22,57$ & $-52,42$ \\
\hline 9 & C7-037 & 410 & $-21,35$ & $-50,68$ & 37 & D9-015 & 240 & $-22,58$ & $-53,07$ \\
\hline 10 & C6-090 & 430 & $-21,45$ & $-49,57$ & 38 & D9-016 & 260 & $-22,58$ & $-52,82$ \\
\hline 11 & C6-093 & 490 & $-21,53$ & $-49,15$ & 39 & D6-100 & 580 & $-22,58$ & $-49,82$ \\
\hline 12 & C6-059 & 420 & $-21,53$ & $-49,87$ & 40 & D7-068 & 330 & $-22,63$ & $-50,90$ \\
\hline 13 & C7-016 & 480 & $-21,57$ & $-50,33$ & 41 & D7-020 & 560 & $-22,63$ & $-50,40$ \\
\hline 14 & C5-093 & 480 & $-21,58$ & $-48,82$ & 42 & D7-041 & 460 & $-22,67$ & $-50,62$ \\
\hline 15 & C5-119 & 430 & $-21,60$ & $-48,97$ & 43 & D8-006 & 340 & $-22,72$ & $-51,13$ \\
\hline 16 & C5-101 & 490 & $-21,85$ & $-48,80$ & 44 & D7-057 & 350 & $-22,73$ & $-50,80$ \\
\hline 17 & C6-050 & 380 & $-21,88$ & $-49,23$ & 45 & D6-095 & 460 & $-22,75$ & $-49,73$ \\
\hline 18 & C5-029 & 450 & $-21,90$ & $-49,03$ & 46 & D6-032 & 480 & $-22,78$ & $-49,93$ \\
\hline 19 & C5-055 & 500 & $-21,98$ & $-48,80$ & 47 & D5-019 & 780 & $-22,82$ & $-48,43$ \\
\hline 20 & D5-003 & 590 & $-22,08$ & $-48,18$ & 48 & D6-104 & 480 & $-22,83$ & $-49,82$ \\
\hline 21 & D5-035 & 445 & $-22,15$ & $-48,75$ & 49 & D7-056 & 400 & $-22,85$ & $-50,55$ \\
\hline 22 & D7-077 & 440 & $-22,17$ & $-50,98$ & 50 & D7-054 & 370 & $-22,90$ & $-50,73$ \\
\hline 23 & D7-036 & 550 & $-22,22$ & $-50,88$ & 51 & E6-035 & 580 & $-23,15$ & $-49,18$ \\
\hline 24 & D6-057 & 580 & $-22,30$ & $-49,15$ & 52 & E6-036 & 610 & $-23,18$ & $-49,03$ \\
\hline 25 & D9-006 & 380 & $-22,30$ & $-52,08$ & 53 & E6-006 & 571 & $-23,22$ & $-49,23$ \\
\hline 26 & D5-008 & 700 & $-22,37$ & $-48,38$ & 54 & E6-002 & 630 & $-23,23$ & $-49,47$ \\
\hline 27 & D9-002 & 440 & $-22,37$ & $-52,32$ & 55 & E6-034 & 640 & $-23,30$ & $-49,15$ \\
\hline 28 & D6-094 & 540 & $-22,43$ & $-49,92$ & & & & & \\
\hline
\end{tabular}

Fonte: DAEE, 2017.

\section{RESULTADOS E ANÁLISE DOS DADOS}

\subsection{FREQUÊNCIA DE DIAS DE CHUVA PARA DIFERENTES LIMIARES NOS SEMESTRES CHUVOSOS}

A aplicação dos procedimentos metodológicos para os semestres chuvosos resultou em um total de doze mapas, representando o produto da distribuição espacial dos índices de dimensão fractal para os três anos padrão (1983 chuvoso, 1984 habitual e 1985 seco), em quatro diferentes limiares previamente estabelecidos (valores acima de $0,1 \mathrm{~mm}, 10 \mathrm{~mm}, 20 \mathrm{~mm}$ e $40 \mathrm{~mm}$ ), contando cada um com uma legenda própria de classes e coloração devido à elevada variabilidade nos dados resultantes. As Figuras 3 e 4 permitem conferir os resultados desta etapa, ilustrados através de mapeamento.

O limiar de 0,1 milímetros apresentou valores da dimensão fractal que variaram entre 0,80 e 0,92 para o período de 1983-1984, entre 0,77 e 0,91 para o período de 1984-1985, e entre 0,77 a 0,88 para o período de 1985-1986, correspondendo ao índice de dias chuvosos no intervalo avaliado: entre 0 (nenhum dia de chuva) a 1 (todos os dias com chuva acima de $0,1 \mathrm{~mm}$ ). Ao analisar os valores da dimensão fractal para os três períodos, de maneira geral, pode-se considerar que estes apresentam pequenas amplitudes entre os valores mínimos e máximos. Dentre eles, foi o período de 1983-1984 que apresentou os maiores valores ao longo de toda a área de estudo, consequentemente revelando uma maior regularidade de dias que tiveram ocorrência de precipitação no total dos 192 dias avaliados, enquanto os dois anos posteriores 
já apresentaram valores mais reduzidos, principalmente na porção sul da área de estudo, com destaque para o Pontal do Paranapanema.

Em relação ao limiar de 10 milímetros, além da distribuição dessas chuvas serem menores em relação ao limiar anterior, houve uma maior amplitude nos valores de dimensão fractal nos meses chuvosos, sendo entre 0,57 a 0,74 em 1983-1984, 0,60 a 0,74 para o período 1984-1985 e um valor entre 0,52 a 0,71 no período 1985-1986. Durante o semestre compreendido entre 1983 a 1984, a classe de maior valor foi verificada na porção do Tietê Batalha e Tietê- Jacaré, apresentando menores valores no setor meridional do Alto Paranapanema. Para período de 1984-85, a classe superior apresentou alguns registros isolados nos baixos cursos das duas bacias, enquanto entre os anos 1985 e 1986, houve uma situação quase inversa ao ano padrão chuvoso (1983-1984), resultando em classes de menor valor no médio curso do rio Tietê.

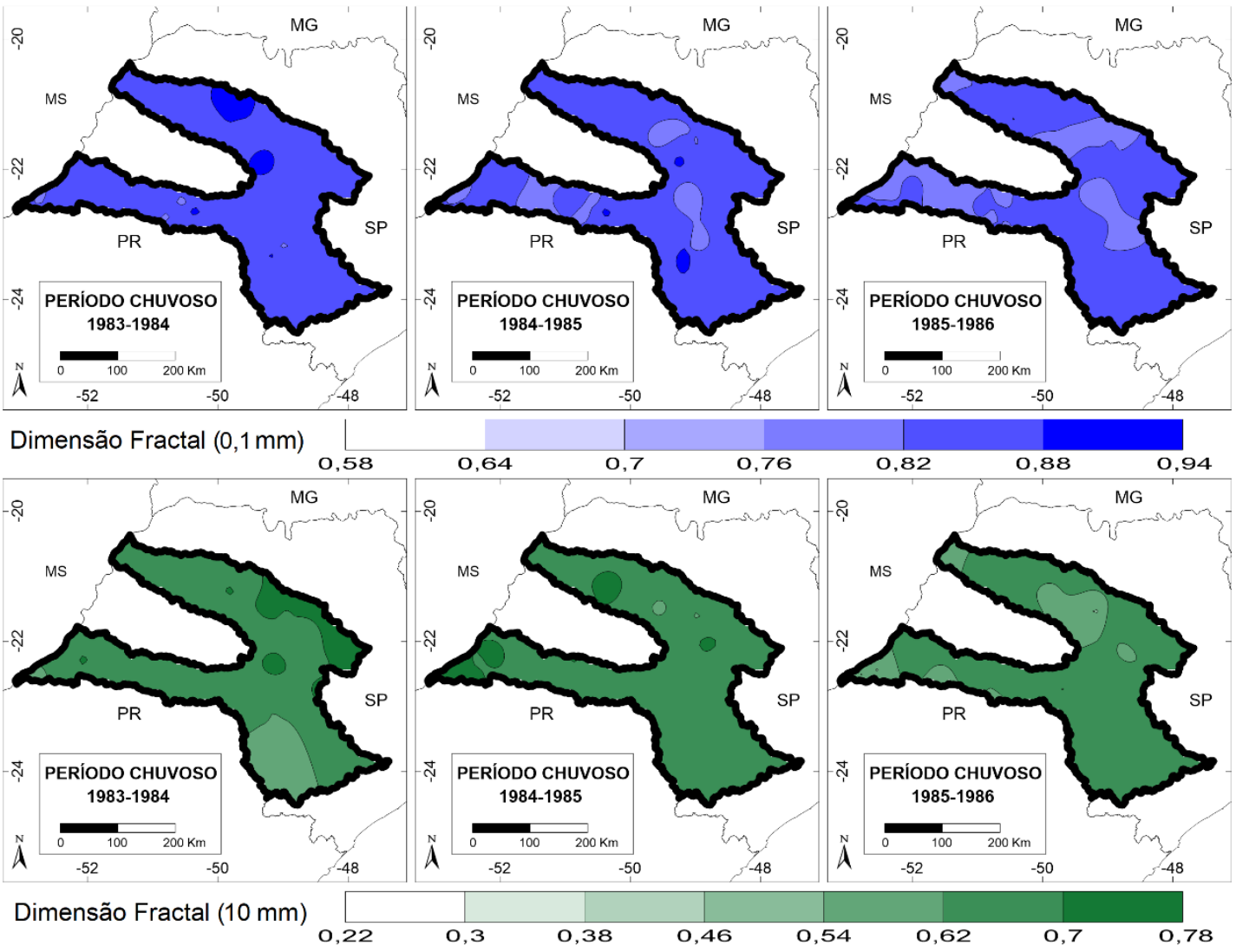

Figura 3 - Dimensão Fractal do semestre chuvoso: limiares de 0,1 e $10 \mathrm{~mm}$.

Nos mapas que representam o limitar de 20 milímetros, já foi possível verificar valores mais reduzidos e uma maior amplitude de dados. Os valores de dimensão fractal assinalam intervalos entre 0,39 a 0,63 para o período de 19831984, entre 0,44 e 0,65 para o período de 1984-1985 e entre 0,36 e 0,62 para a estação chuvosa de 1985-1986. Durante o período 1983-1984, pode-se verificar valores de classes mais elevados no setor norte, ou seja, na bacia do Tietê em relação ao Paranapanema. Em relação ao segundo mapa desse limiar, referente ao semestre entre os anos 1984-1985, houve uma distribuição mais 
abrangente de valores entre 0,50 e 0,60 de dimensão fractal, exceto em alguns pontos isolados e no Alto Paranapanema, que apresentou valores acima de 0,60. No período 1985-1986, a classe superior aos valores de 0,50 encontra-se no Médio Paranapanema e adjacências, abrangendo também a maior parcela da região hidrográfica do Tietê, com destaque para a porção setentrional.

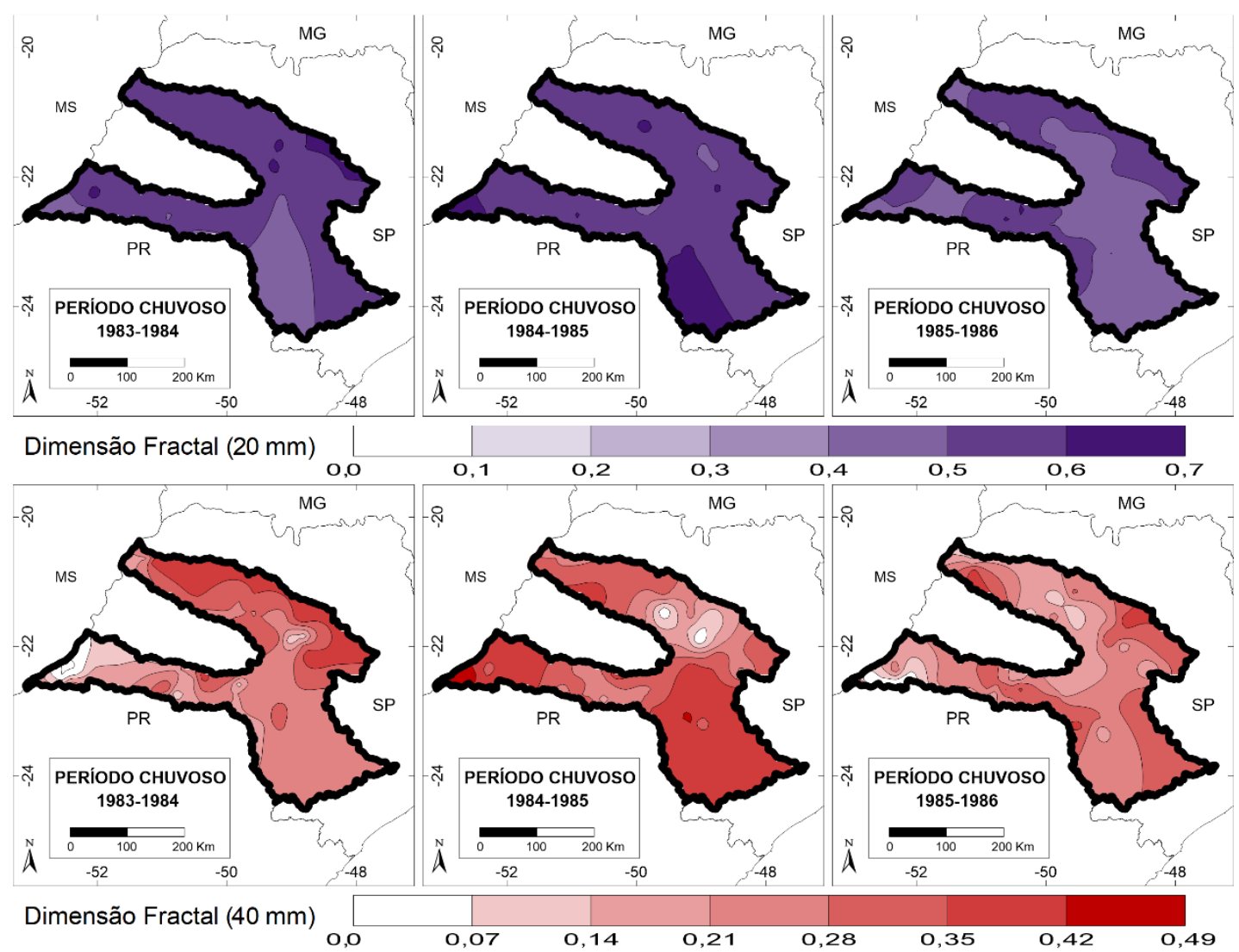

Figura 4 - Dimensão Fractal do semestre chuvoso: limiares de 20 e $40 \mathrm{~mm}$.

Para o limiar de 40 milímetros, resultante da concentração de chuvas mais volumosas, ambos os três períodos apresentaram valores de dimensão fractal que oscilam a partir do zero, chegando até o valor máximo de 0,40 entre 1983-1984, a grandeza de 0,49 entre 1984-1985 e o número de 0,38 entre 1985-1986. Nele, já foi possível observar oscilações mais nítidas nos mapas, com destaque para valores mais acentuados na bacia do Tietê em relação ao Paranapanema no período entre 1983-1984, repercussão muito diferente da ocorrida entre 1984-1985, que apresentou baixos valores no Tietê - Batalha e Tietê - Jacaré em relação ao entorno da área de estudo, e um outro cenário distinto entre 1985-1986, com predominância de classes de menor valor ao longo da extensão analisada e somente alguns setores de maior dimensão fractal, como é o caso do nordeste da área de estudo, alguns trechos próximos à jusante do Baixo Tietê e no Médio Paranapanema.

No geral, notou-se uma diminuição do número de dias com ocorrência de precipitação conforme aumentou-se os limiares, ou seja, o número de dias com 
chuvas mais intensas nos semestres chuvosos estabelecidos. No caso do período 1985-1986, tal oscilação mostrou-se mais intensa que os outros anos, evidenciando o menor número de chuvas volumosas nesse intervalo. No período 1983-1984, a porção norte (setores da bacia do Tietê) ao longo dos limiares variou pouco em relação ao sul da área de estudo, resultando em chuvas mais intensas no setor norte, inferência que se difere do observado no ano posterior (1984-1985), com chuvas diárias mais intensas ao sul da área de estudo. À vista disso, pode-se sinalizar uma circulação atmosférica diferenciada entre ambos os anos avaliados.

\subsection{FREQUÊNCIA DE DIAS DE CHUVA PARA DIFERENTES LIMIARES NOS SEMESTRES SECOS}

Assim como no tópico anterior, nessa etapa foram aplicados os procedimentos metodológicos para os semestres secos dos anos-padrão, resultando em doze mapas exibindo a distribuição dos valores de dimensão fractal para os quatro diferentes limiares. As legendas de cores e as classes estabelecidas para os semestres chuvosos para cada um dos valores foram padronizadas e mantidas iguais nessa etapa, com a finalidade de tornar possível a comparação entre o período chuvoso e seco a partir dos quatro limiares. As Figuras 5 e 6 ilustram e permitem conferir os mapas resultantes.

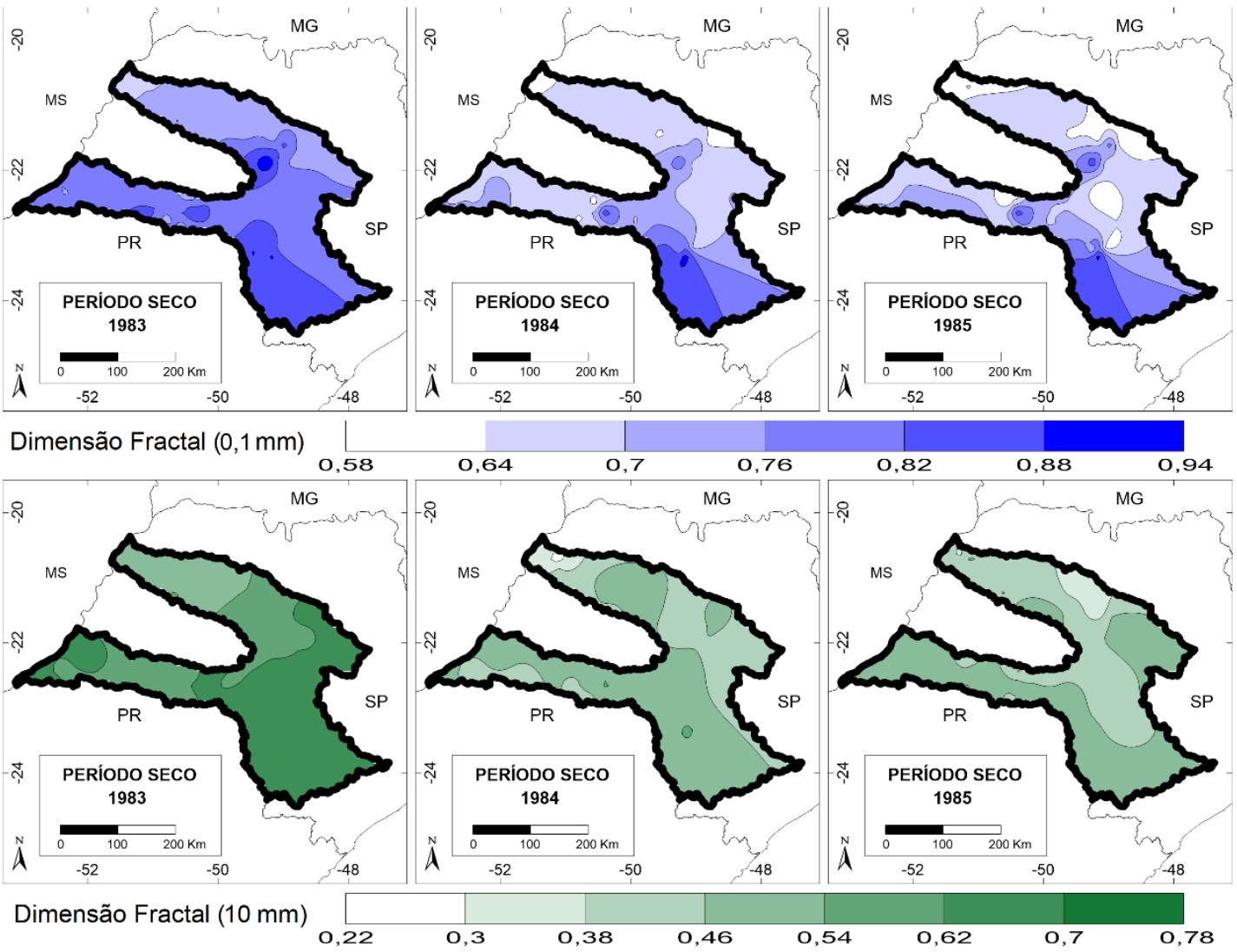

Figura 5 - Dimensão Fractal do semestre seco: limiares de 0,1 e $10 \mathrm{~mm}$. 
Nos três primeiros mapas, representando os valores no limiar de 0,1 milímetros, já é possível verificar um resultado nitidamente distinto do período chuvoso anterior, assinalando valores com maior amplitude de dimensão fractal, que variam entre 0,66 e 0,94 no ano de 1983, 0,61 a 0,91 em 1984 e 0,58 a 0,92 para o ano de 1985. Entretanto, a amplitude geral do ano-padrão chuvoso (1983) apresenta-se menor que as anteriores, além de resultar em valores mais elevados no setor meridional da área de estudo, principalmente no Alto Paranapanema. Os valores mais elevados ao sul da região analisada mantem-se nos anos posteriores, com destaque ainda para alguns pontos de classes mais elevadas na unidade do Tietê - Batalha, porém no geral com classes inferiores às do ano chuvoso, apresentando menores valores de dimensão fractal principalmente no ano de 1985.

No limiar de 10 milímetros, são observados valores de dimensão fractal que variam entre 0,48 a 0,67 no ano de 1983, 0,22 a 0,55 para 1984 e 0,32 e 0,55 no ano de 1985. De maneira geral, fica nítido a magnitude dos dados do ano-padrão chuvoso em relação aos outros dois, além de menores valores ao norte da área de estudo se comparado à porção setentrional, com destaque para o Baixo Tietê em 1983, o setor mais próximo à jusante do Baixo Tietê em 1984 e Tietê - Batalha em 1985.

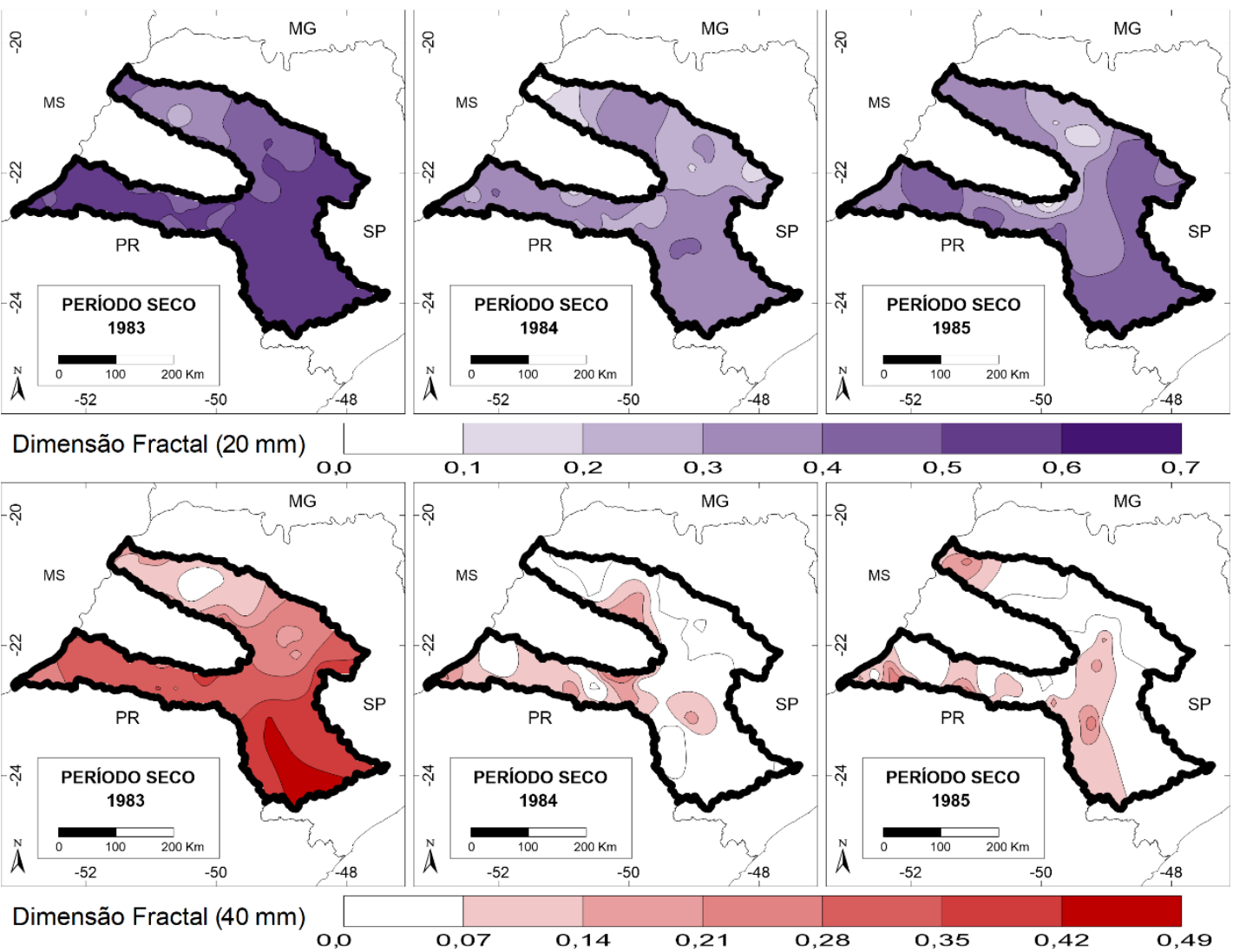

Figura 6 - Dimensão Fractal do semestre seco: limiares de 20 e 40 mm.

Em relação ao limiar de 20 milímetros, notou-se uma amplitude considerável nos valores entre 0,27 e 0,59 de dimensão fractal do ano de 1983, 
enquanto nos dois períodos posteriores os dados oscilam a partir de zero até 0,48 . No ano de 1983, nota-se valores de classes mais altas em relação aos dois anos posteriores, e uma menor intensidade no Baixo Tietê. Para o ano 1984, no geral o Tietê - Jacaré e o setor mais próximo à jusante do Baixo Tietê mostraram-se dotados de valores inferiores em relação ao restante do mapa. No ano de 1985, já é possível notar que a unidade do Tietê - Batalha passa apresentar menores valores em relação às demais áreas, evidenciando chuvas menos concentradas.

$\mathrm{Na}$ análise do limiar de 40 milímetros, os dados de dimensão fractal partem de zero e oscilam até os valores e 0,45 no ano de 1983, 0,29 em 1984 e 0,27 para o ano de 1985. Além da elevada amplitude de classes observada, destaca-se novamente a nítida diferença entre o ano-padrão chuvoso de 1983 em relação aos demais, pois enquanto no primeiro predominaram classes de números mais elevados, exceto no Baixo Tietê, os anos de 1984 e 1985 exprimiram valores baixos na maior parte da área de estudo, principalmente na bacia do Tietê.

Do mesmo modo que no semestre chuvoso, analisado anteriormente, observou-se de maneira geral uma diminuição do número de dias com ocorrência de chuvas conforme elevou-se os limiares, todavia, neste semestre seco a oscilação mostrou-se muito mais intensa que no outro. Ademais, o ano 1983 destoou nitidamente em relação aos outros, denotando um caráter chuvoso para tal semestre habitualmente mais seco. Por fim, notou-se que na porção sul (setores da bacia do Paranapanema) as variações foram menos acentuadas, aproximando-se do que propõe Monteiro (1973) ao avaliar a entrada de frentes frias de forma mais intensa durante o outono-inverno ao sul do estado de São Paulo.

\section{CONSIDERAÇÕES FINAIS}

Em termos gerais, observou-se por meio do material cartográfico produzido nessa pesquisa uma diminuição da frequência de dias chuvosos e dos índices de dimensão fractal conforme aumentou-se a magnitude dos limiares, ou seja, o número de dias com chuvas intensas. No entanto, tal decréscimo mostrou-se mais sensível nos semestres secos, com destaque para os anos 1984 e 1985, enquanto nos semestres chuvosos notou-se uma menor variabilidade de dias chuvosos entre os três anos-padrão ao longo dos diferentes limiares.

Em relação à altitude e forma do relevo da área, foi possível verificar valores mais elevados de dimensão fractal em regiões de relevo mais elevado em relação às adjacências. Entretanto, somente esse efeito não explica toda a situação pluviométrica da região, cujos setores da bacia do Tietê apresentaram predomínio de valores menores comparados à bacia do Paranapanema ao longo do semestre seco, possivelmente associados à entrada de sistemas frontais ao sul da área de estudo. Já nos semestres chuvosos, os valores resultantes em parâmetros latitudinais alternaram-se ao longo dos três anos, evidenciando respostas pluviais distintas às condições de relevo e, possivelmente, à circulação atmosférica do período (ano-padrão).

Nos três setores da bacia do Tietê, ao longo do período chuvoso, foi possível observar índices de dimensão fractal mais elevados no setor Tietê- 
Jacaré e nas proximidades da jusante e ao norte do Baixo Tietê, enquanto foram verificados valores menores no setor Tietê-Jacaré. De maneira geral, o ano de 1983 apresentou-se muito chuvoso ao longo do período, apresentando uma participação de classes mais elevadas de dimensão fractal, mesmo para o limiar de 40 milímetros, ao mesmo tempo que os anos de 1984 e 1985 apresentaram uma predominância de classes menores estabelecidas nesse limiar. Em termos gerais, nos dois períodos o limiar de 20 milímetros já permitia visualizar tais considerações, porém o limiar de 40 milímetros deixou os resultados ainda mais nítidos.

Na bacia hidrográfica do Paranapanema, o semestre chuvoso mostrou-se variável ao longo dos períodos. A primavera-verão de 1983-1984 na região apresentou características distintas em relação à bacia do Tietê, resultando em menores valores de dimensão fractal principalmente no setor do Pontal do Paranapanema e, apesar da área como um todo apresentar resultados superiores ao ano-padrão seco de 1985-1986, produziu classes de valores inferiores se comparado ao período de 1984-1985, com destaque para os setores do Pontal e Alto Paranapanema. No período seco, o setor do Alto Paranapanema exibiu valores mais elevados de dimensão fractal em relação aos outros ao longo dos limiares, porém o ano de 1983 destacou-se se comparado aos demais pela alta precipitação no período, inclusive nos limiares de volume mais elevados.

A aplicação de técnicas de análise multifractal para as duas bacias produziu semelhanças bastante evidentes em relação à descrição dos climas do Estado de São Paulo realizada pelo professor Carlos Augusto de Figueiredo Monteiro, que foi pautada, sobretudo, pela análise do ritmo pluviométrico. Desta forma, a dimensão fractal exprimiu numericamente a variabilidade das chuvas e comprovou-se aplicável como sendo um parâmetro quantitativo para o prosseguimento de pesquisas que visem a aplicação da análise rítmica, não apenas no aspecto temporal, mas também na espacialização dos dados. Assim, pode-se afirmar que os objetivos deste trabalho foram atingidos e abrem-se novos desafios para verificar a importância destas técnicas em outras bacias paulistanas usando como parâmetro o ritmo das precipitações e a sua relação com a dinâmica climática.

\section{REFERÊNCIAS BIBLIOGRÁFICAS}

AB'SÁBER, A. N. Os domínios de natureza no Brasil: potencialidades paisagísticas. São Paulo: Ateliê Editorial, 2003.

BRASIL. Ministério do Interior. Secretaria Especial do Meio Ambiente. Relatório de Qualidade do Meio Ambiente, Brasília, DF, 1984.

BRASIL. Ministério dos Transportes. Informações detalhadas sobre o Rio Tietê. Disponível em: <http://www.transportes.gov.br/bit/hidro/detriotiete.htm/>. Acesso em: 15 ago. 2017.

CHORLEY, R. J.; KENNEDY, B. A. Physical geography: a systems approach. London, England: Prentice-Hall, 1971.

CHRISTOFOLETTI, A. A análise de bacias hidrográficas, Geomorfologia, v. 2, p. 102-127, 1980. 
CHRISTOFOLETTI, A. Modelagem de Sistemas Ambientais. São Paulo: Edgard Blücher, 1999.

CHRISTOFOLETTI, A. L. H. Análise da sazonalidade da precipitação na Bacia do Piracicaba (SP), Geografia, Rio Claro, v. 17, n. 2, p. 93-105, 1992.

CHRISTOFOLETTI, A. L. H. Análise fractal e multifractal da estrutura de estações chuvosas em localidades do Estado de São Paulo. 1997. Tese (doutorado em Geociências e Meio Ambiente) - Instituto de Geociências e Ciências Exatas, Universidade Estadual Paulista, Rio Claro, 1997.

CHRISTOFOLETTI, A. L. H. Sistemas Dinâmicos: as abordagens da teoria do caos e da geometria fractal em geografia In: VITTE, A. C.; GUERRA, J. T. Reflexões sobre a geografia física do Brasil. Rio de Janeiro, Bertand Brasil, 2004.

DAEE. Departamento de Águas e Energia Elétrica do Estado de São Paulo. Disponível em: <http://www.daee.sp.gov.br/>. Acesso em 08 ago. 2017.

FONTÃO, P. A. B.; ZAVATTINI, J. A. Variations of Rainfall Rhythm in Alto Pardo Watershed, Brazil: Analysis of Two Specific Years, a Wet and a Dry One, and Their Relation with the River Flow. Climate, v. 5, n. 3, p. 47, 2017.

GLEICK, J. Caos: a criação de uma nova ciência. Rio de Janeiro: Campus, 1990.

GUERRINI, I. A. Caos e fractais em Física Aplicada. Botucatu-SP: IB/Unesp, 1996.

HAIGH, M. J. Geography and general system theory, philosophical homologies and current practice, Geoforum, v. 16, n. 2, p. 191-203, 1985.

JEBARI, S.; BERNDTSSON, R.; OLSSON, J.; BAHRI, A. Soil erosion estimation based on rainfall disaggregation, Journal of hydrology, v. 436, p. 102-110, 2012.

KANTELHARDT, J. W.; KOSCIELNY-BUNDE, E.; RYBSKI, D.; BRAUN, P.; BUNDE, A.; HAVLIN, S. Long-term persistence and multifractality of precipitation and river runoff records. Journal of Geophysical Research: Atmospheres, v. 111, n. D1, 2006.

LORENZ, E. N. A essência do caos. Brasília: Editora UNB, 1996.

MANDELBROT, B. B. Les Objets fractals, forme, hasard et dimension. Paris, France: Flammarion, 1975.

MANDELBROT, B. B. The fractal geometry of nature. New York, USA: W. H. Freeman and Company, 1982.

MAYER, L. Fractal characteristics of desert storm sequences and implications for geomorphic studies, Geomorphology, v. 5, n. 1-2, p. 167-183, 1992.

MELLO, G. J.; PAULO, I. J. C.; PAULO, S. R.; GOMES, R. S. R.; MACHADO, N. G.; NOGUEIRA, J. S.; BIUDES, M. S.; Dimensão fractal de séries temporais medidas acima do dossel da floresta no pantanal mato-grossense, Revista Brasileira de Climatologia, v. 12, p. 61-83, 2013.

MONTEIRO, C. A. F: A Frente Polar Atlântica e as Chuvas de Inverno na Fachada Sul-Oriental do Brasil (Contribuição metodológica à análise rítmica dos tipos de tempo no Brasil). São Paulo: USP/IG, 1969. 
MONTEIRO, C. A. F. A Dinâmica Climática e as Chuvas no Estado de São Paulo: estudo geográfico sob a forma de atlas. São Paulo: USP/IG, 1973.

MONTEIRO, C. A. F. (Org.) A construção da Climatologia Geográfica no Brasil. $1^{a}$ Edição. Campinas-SP: Editora Alínea, 2015.

OLSSON, J. Scaling and fractal properties of rainfall-analysis and modeling of rain gauge data. Lund, Sweden: University of Lund - Department of Water Resources Engineering, 1996.

PEITGEN, H. O.; JURGENS, H.; SAUPE, D. Chaos and fractals: new frontiers of science. New York, USA: Springer Verlag, 1992.

PEREIRA A.; CHRISTOFOLETTI A. L. H. Análise Fractal da Distribuição Espacial das Chuvas no Estado de São Paulo, Geografia, Rio Claro, v. 28, n. 1, p. 97-133, 2003.

PRIGOGINE, I. Time, dynamics and chaos. Integrating Poincare's "nonintegrable systems". Austin, Texas (USA): Texas University, Center for Statistical Mechanics and Complex Systems, 1990.

SANT'ANNA NETO, J. L. As chuvas no Estado de São Paulo: contribuição ao estudo da variabilidade e tendência da pluviosidade na perspectiva da análise geográfica. São Paulo: USP/FFLCH, 1995.

SIGRH. Sistema Integrado de Gerenciamento de Recursos Hídricos do Estado de São Paulo. Disponível em: <http://www.sigrh.sp.gov.br/>. Acesso em 02 out. 2017.

SOTCHAVA, V. B. O estudo de geossistemas. São Paulo: USP/IG, 1977.

STRAHLER, A. N. Physical Geography. New York: John Willey \& Sons, 1951.

XAVIER JÚNIOR, S. F. A.; STOSIC, T.; STOSIC, B.; JALE, J. S.; XAVIER, E. F. M. A Brief multifractal analysis of rainfall dynamics in Piracicaba, São Paulo, Brasil. Acta Scientiarum. Technology, v. 40, p. e35116, 2018.

ZANDONADI, L. As Chuvas na Bacia do Paraná: aspectos temporais, espaciais e rítmicos (Dissertação de Mestrado). Rio Claro: UNESP, 2009. 122 p.

ZAVATTINI, J. A. Estudos do Clima no Brasil. Campinas-SP: Editora Alínea, 2004. 398 p. 